\title{
Growth Inhibition of Re-Challenge B16 Melanoma Transplant by Conjugates of Melanogenesis Substrate and Magnetite Nanoparticles as the Basis for Developing Melanoma-Targeted Chemo-Thermo-Immunotherapy
}

\author{
Tomoaki Takada, ${ }^{1}$ Toshiharu Yamashita, ${ }^{1}$ Makito Sato, ${ }^{1}$ Akiko Sato, ${ }^{1}$ Ichiro Ono, ${ }^{1}$ \\ Yasuaki Tamura, ${ }^{2}$ Noriyuki Sato, ${ }^{2}$ Atsushi Miyamoto, ${ }^{3}$ Akira Ito, ${ }^{4}$ Hiroyuki Honda, ${ }^{5}$ \\ Kazumasa Wakamatsu, ${ }^{6}$ Shosuke Ito, ${ }^{6}$ and Kowichi Jimbow ${ }^{1,7}$ \\ ${ }^{1}$ Department of Dermatology, Sapporo Medical University School of Medicine, Sapporo 060-8543, Japan \\ ${ }^{2}$ Department of Pathology 1, Sapporo Medical University School of Medicine, Sapporo 060-8556, Japan \\ ${ }^{3}$ Division of Pharmaceutical Health Care and Sciences, Sapporo Medical University School of Medicine, Sapporo 060-8556, Japan \\ ${ }^{4}$ Department of Chemical Engineering, Faculty of Engineering, Kyushu University, Fukuoka 812-8581, Japan \\ ${ }^{5}$ Department of Biotechnology, School of Engineering, Nagoya University, Nagoya 464-8603, Japan \\ ${ }^{6}$ Department of Chemistry, Fujita Health University School of Health Sciences, Aichi 470-1192, Japan \\ ${ }^{7}$ Department of Cutaneous Sciences, Institute of Dermatology \& Cutaneous Sciences, 060-0042, Japan
}

Correspondence should be addressed to Kowichi Jimbow, jimbow@sapmed.ac.jp

Received 3 April 2009; Accepted 15 July 2009

Recommended by Dominic Fan

Melanogenesis substrate, N-propionyl-cysteaminylphenol (NPrCAP), is selectively incorporated into melanoma cells and inhibits their growth by producing cytotoxic free radicals. Magnetite nanoparticles also disintegrate cancer cells and generate heat shock protein (HSP) upon exposure to an alternating magnetic field (AMF). This study tested if a chemo-thermo-immunotherapy (CTI therapy) strategy can be developed for better management of melanoma by conjugating NPrCAP on the surface of magnetite nanoparticles (NPrCAP/M). We examined the feasibility of this approach in B16 mouse melanoma and evaluated the impact of exposure temperature, frequency, and interval on the inhibition of re-challenged melanoma growth. The therapeutic protocol against the primary transplanted tumor with or without AMF exposure once a day every other day for a total of three treatments not only inhibited the growth of the primary transplant but also prevented the growth of the secondary, re-challenge transplant. The heat-generated therapeutic effect was more significant at a temperature of $43^{\circ} \mathrm{C}$ than either $41^{\circ} \mathrm{C}$ or $46^{\circ} \mathrm{C}$. NPrCAP/M with AMF exposure, instead of control magnetite alone or without AMF exposure, resulted in the most significant growth inhibition of the re-challenge tumor and increased the life span of the mice. HSP70 production was greatest at $43^{\circ} \mathrm{C}$ compared to that with $41^{\circ} \mathrm{C}$ or $46^{\circ} \mathrm{C}$. CD $8^{+} \mathrm{T}$ cells were infiltrated at the site of the re-challenge melanoma transplant.

Copyright (C) 2009 Tomoaki Takada et al. This is an open access article distributed under the Creative Commons Attribution License, which permits unrestricted use, distribution, and reproduction in any medium, provided the original work is properly cited.

\section{Introduction}

Melanogenesis is inherently cytotoxic and uniquely occurs in melanocytic cells; thus, tyrosine analogs that are tyrosinase substrates are good candidates for melanoma-specific targeting and therapy [1]. $N$-propionyl and $N$-acetyl derivatives of 4-S-cysteaminylphenol (NPr- and NAcCAP) were synthesized and found to possess both cytostatic and cytocidal effects on in vivo and in vitro melanomas through the oxidative stress resulting from production of cytotoxic free radicals [2-6]. We now provide evidence that the unique melanogenesis cascade can be exploited for developing a chemo-thermo-immunologic approach (CTI Therapy) targeted to melanoma by conjugating NPrCAP with magnetite nanoparticles (NPrCAP/M).

Magnetite nanoparticles have been employed for thermotherapy in a number of cancer treatments including human prostate cancers [7-9]. They consist of $10-100 \mathrm{~nm}$ 
sized iron oxide $\left(\mathrm{Fe}_{3} \mathrm{O}_{4}\right)$ with a surrounding polymer coating and become magnetized when placed in an external alternating magnetic field (AMF) [10]. In hyperthermia treatment, the expression of heat shock proteins (HSPs) plays an important role in immune reactions [11-19]. Accumulating evidence from our group [20-23] and from others [24] implicates HSP expression induced by hyperthermia in tumor immunity and opens the door to cancer therapy based on hyperthermia treatment (thermo-immunotherapy). In such a strategy, a tumor-specific hyperthermia system that can induce necrotic cell death via HSP expression without damaging noncancerous tissues would be highly desirable. An intracellular hyperthermia system using tumor-targeted magnetite nanoparticles facilitates tumor-specific hyperthermia; this can induce necrotic cell death via HSP expression, which in turn induces antitumor immunity.

We synthesized, in our initial study, magnetite cationic liposomes (MCLs) loaded with 4-S-cysteaminylphenol (CAP) [25]. There was, however, a risk of nonspecific electrostatic interaction between MCLs and various nontarget cells. A promising technique is the use of tumortargeted magnetite nanoparticles, and this approach is extended by synthesizing another type of magnetite nanoparticles, NPrCAP/M, on which NPrCAP is superficially and directly bound on the surface of magnetite nanoparticles. NPrCAP/M is chemically stable and can be produced in large quantities and employed to effect melanoma-targeted chemotherapy (by NPrCAP) and thermoimmunotherapy (by magnetite with HSP). In this study, we evaluated their thermo-therapeutic effect on distant metastatic melanomas, using the mouse B16 melanoma system. Specifically we assessed the in vivo growth inhibition of a subsequently transplanted melanoma growth (re-challenge melanoma) after treating the initial melanoma transplant. We also investigated the possible association of HSP production with growth inhibition of the re-challenge melanoma.

\section{Materials and Methods}

2.1. Preparation of NPrCAP/M. The details of the preparation of NPrCAP/M are described elsewhere [26]. Briefly, magnetite nanoparticles $\left(\mathrm{Fe}_{3} \mathrm{O}_{4}\right.$; average particle size, $\left.10 \mathrm{~nm}\right)$ were coated with aminosilane and conjugated with NPrCAP via maleimide cross-linkers. The resultant $\mathrm{NPrCAP} / \mathrm{M}$ was suspended in $10 \mathrm{~mL}$ of $\mathrm{H}_{2} \mathrm{O}$. The degree of incorporation of NPrCAP to magnetite was $61.0 \mathrm{nmol} / \mathrm{mg}$ magnetite.

2.2. Cells and Animal Models. All of the animal experiments were conducted by an approval of Animal Experiment Ethics Committee of Sapporo Medical University. All the surgical, transplantation and drug administration procedures were carried out after anesthesia by diethyl ether. Mouse B16F1 and B16F10 and B16 OVA melanoma cells $\left(3.0 \times 10^{5}\right)$ in $0.1 \mathrm{~mL}$ of phosphate-buffered saline (PBS) were s.c. transplanted into the right flanks of 4-week-old female C57BL/6 mice (weighing approximately $10.0 \mathrm{~g}$ and purchased from Hokudo Laboratory, Sapporo, Japan). B16F1 and B16F10 cells were purchased from ATCC (Summit Pharmaceuticals
Intl. Corp., Tokyo, Japan). B16OVA is a B16F1 melanoma cell line stably transfected with chicken ovalbumin (OVA) cDNA and was kindly provided by Dr. Y. Nishimura, Kumamoto University, Kumamoto, Japan [27]. On day 5 after transplant mice with primary melanoma transplantation were randomly divided into treatment groups. With a 26-gauge microsyringe, the $\mathrm{B} 16$ melanoma-bearing mice were injected with $0.1 \mathrm{~mL}$ of NPrCAP/M $(40.0 \mathrm{mg} / \mathrm{mL}$ solution) directly into the tumor site in a single-dose administration (approximately $0.5 \mu \mathrm{L} / \mathrm{mm}^{3}$ tumor volume). Treated tumors on the right flank in mice were excised on day 13 after the first s.c. transplantation. On day 40 after the surgical excision (on day 53 after primary transplantation), mice were rechallenged with $1.0 \times 10^{5} \mathrm{~B} 16$ cells which were injected into the left flank. The total number of melanoma cells at the re-challenge experiments was $1 / 3$ of melanoma cells as that of the primary transplants because there was no $\mathrm{NPrCAP} / \mathrm{M}$ administration which might cause some tissue destruction. The control group, naive mice of the same age and sex, received transplantation of melanoma cells into the right flank as with the treated groups. On day 14 after the secondary transplantation (day 67 after primary transplantation), tumor diameters were measured in millimeters with calipers, and tumor volumes were calculated by the formula: long axis $\times(\text { short axis })^{2} \times 0.5$. The mice in the treated groups were judged to be tumor free (rejection) if the tumor was less than about $2 \mathrm{~mm}$ in diameter by palpation on day 60 after the secondary transplantation (day 113 after the primary transplantation).

\subsection{Magnetite-Nanoparticle-Mediated Hyperthermia. An} alternating magnetic field (AMF) was generated using a horizontal coil (inner diameter: $7 \mathrm{~cm}$; length: $7 \mathrm{~cm}$ ) with a transistor inverter (LTG-100-05; Dai-ich High-Frequency Co., Tokyo, Japan). The magnetic field frequency and intensity were $118 \mathrm{kHz}$ and $30.6 \mathrm{kA} / \mathrm{m}$ (384 Oe), respectively. Mice were exposed to the AMF inside the coil for 15 or 30 minutes. Surface (peripheral) and core (central) temperatures of the tumor were continuously monitored and measured using two optical fiber probes (FX-9020; Anritsu Meter, Tokyo, Japan); that is, one inserted into the tumor core and another fixed on the tumor surface. Measurement time points were $0,1,2,3,4,5,10,15$, $20,25,30,31,32,33,34$, and 35 minutes for 30 minutes thermotherapy. The therapeutic temperatures at $41^{\circ} \mathrm{C}$, $43^{\circ} \mathrm{C}$ or $46^{\circ} \mathrm{C}$ were monitored by measuring the surface temperature and adjusting the transistor inverter during exposure to AMF (Figures 1(a), 1(b), and 1(c)).

\subsection{Treatment Protocols. Animal experiments were carried out using the four protocols described below. Each exper- imental group of Protocols number 1 through number 4 consisted of six to eleven mice. All the treatment protocols were again approved by the Animal Experimental Ethics Committee of Sapporo Medical University. The experimental conditions for melanoma transplantation and the methods of NPrCAP/M administration were identical in all four protocols and all the animal experiments including drug}




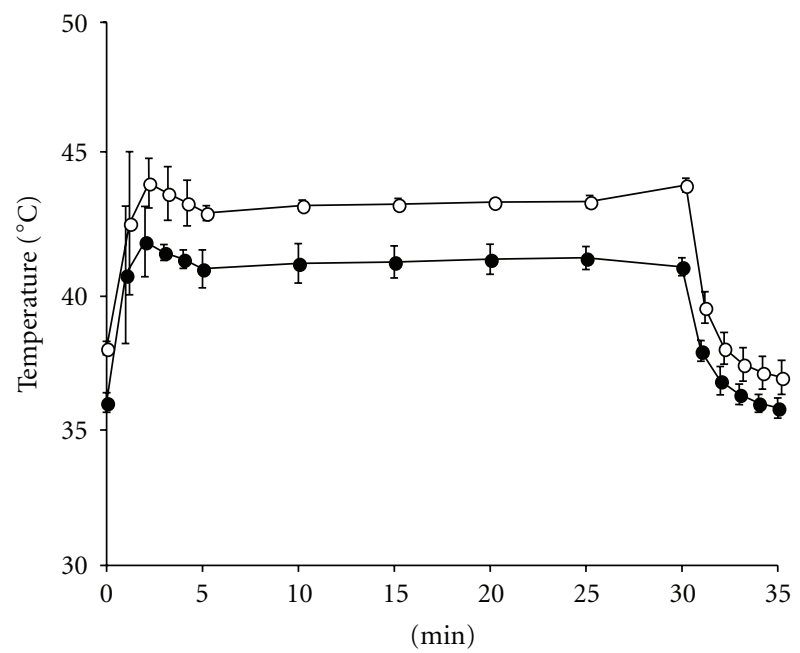

(a)

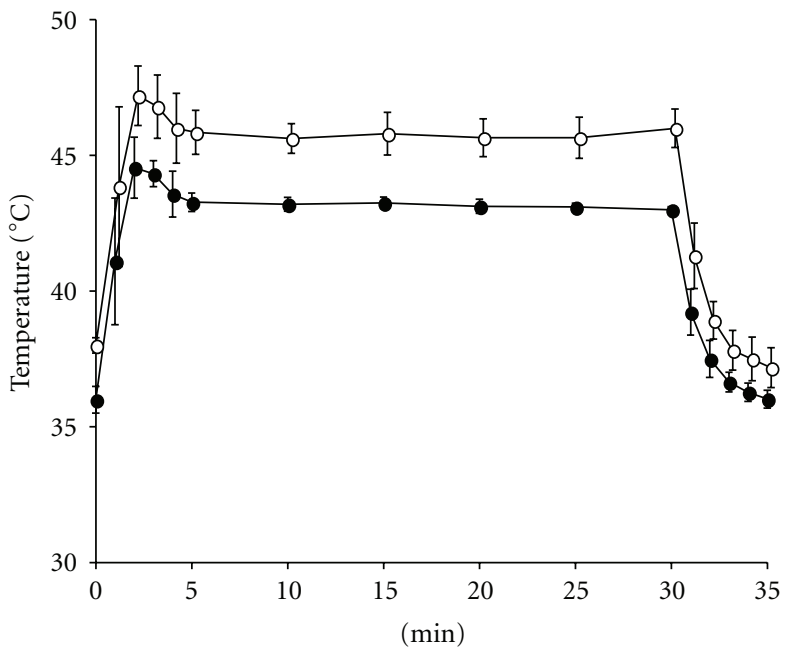

(b)

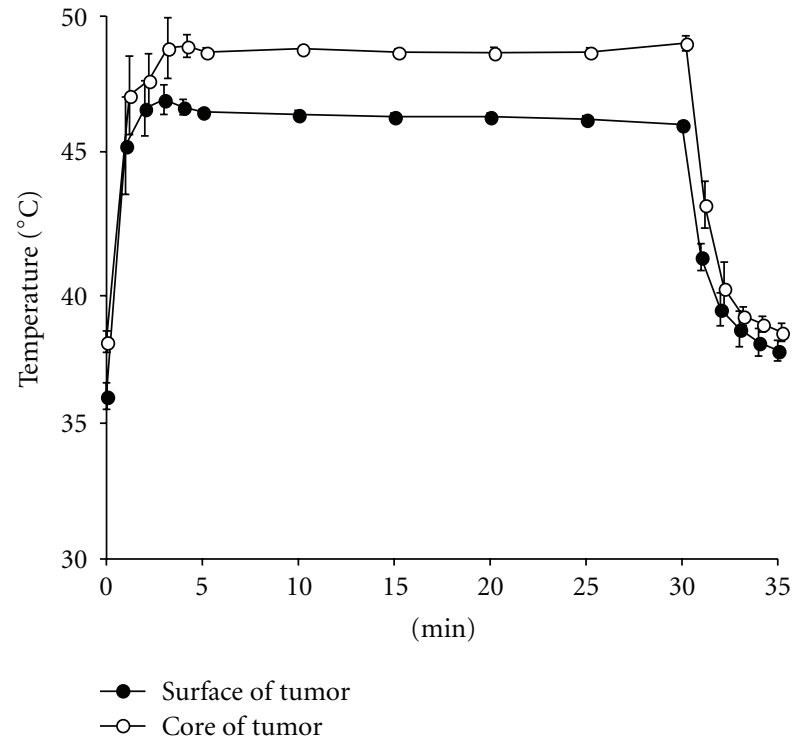

(c)

Figure 1: Shifts of temperatures at the core and the surface of tumors during AMF exposure. The temperature at the tumor surface was maintained at $41^{\circ} \mathrm{C}$ (a), $43^{\circ} \mathrm{C}$ (b), and $46^{\circ} \mathrm{C}$ (c) for 30 minutes by adjusting the power of the AMF generator. Temperatures of both the tumor surface and core were measured simultaneously.

administration were carried out after anesthesia by diethyl ether.

2.4.1. Protocol Number 1: Effect of NPrCAP/M with and without AMF on Re-Challenge Tumor Growth. On day 5 after the s.c. transplantation of B16 melanoma cells, mice were divided into four groups. In Groups I and II mice received s.c. administration of $0.1 \mathrm{~mL}$ of $40.0 \mathrm{mg} / \mathrm{mL}$ aminosilanecoated magnetite $(\mathrm{M})$ once a day every other day for a total of three days (days 6, 8, and 10) with AMF (Group II) or without AMF (Group I). In Groups III and IV mice received s.c. administration of $0.1 \mathrm{~mL}$ of NPrCAP/M $(4.0 \mathrm{mg}$ magnetite equivalent) once a day every other day for a total of three days (days 6, 8, and 10) with (Group IV) or without (Group III) AMF. The temperature at the tumor surface was maintained at $43^{\circ} \mathrm{C}$ during exposure for 30 minutes by controlling AMF intensity. Mice of a control group of the same age and sex received s.c. transplantation of melanoma cells into the right flank, as with the treated groups. On day 13 after the primary transplantation all mice underwent total resection of melanoma nodules. On day 53 after the first transplantation (postoperative day 40), surviving mice in each group received a second transplantation of B16 


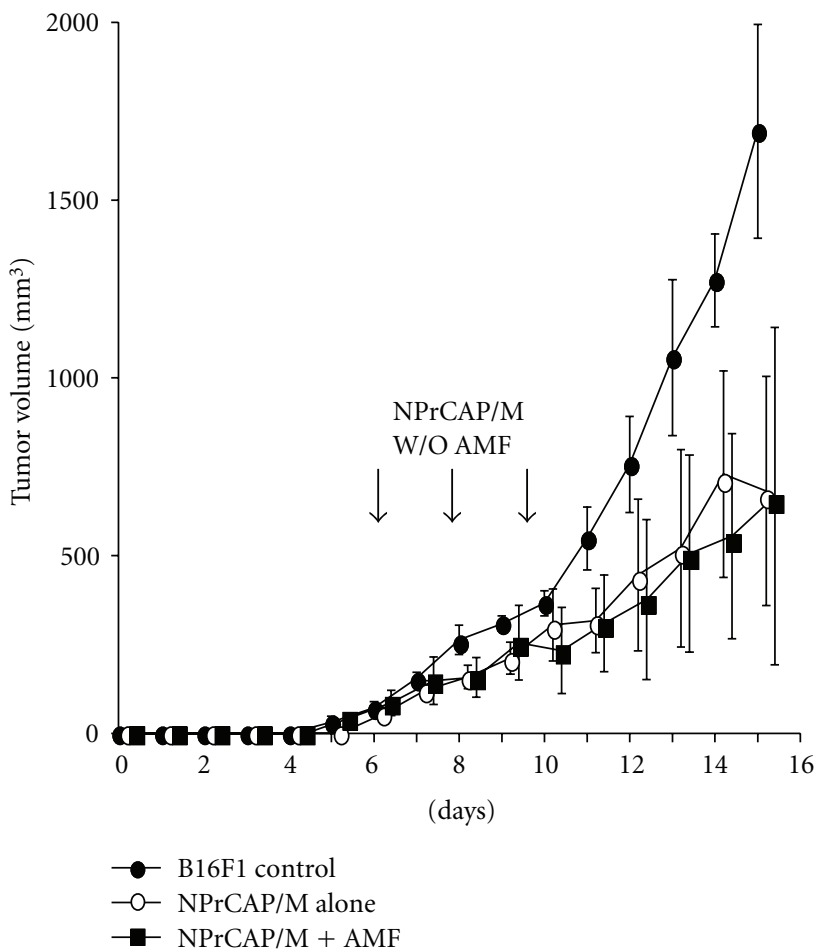

(a)

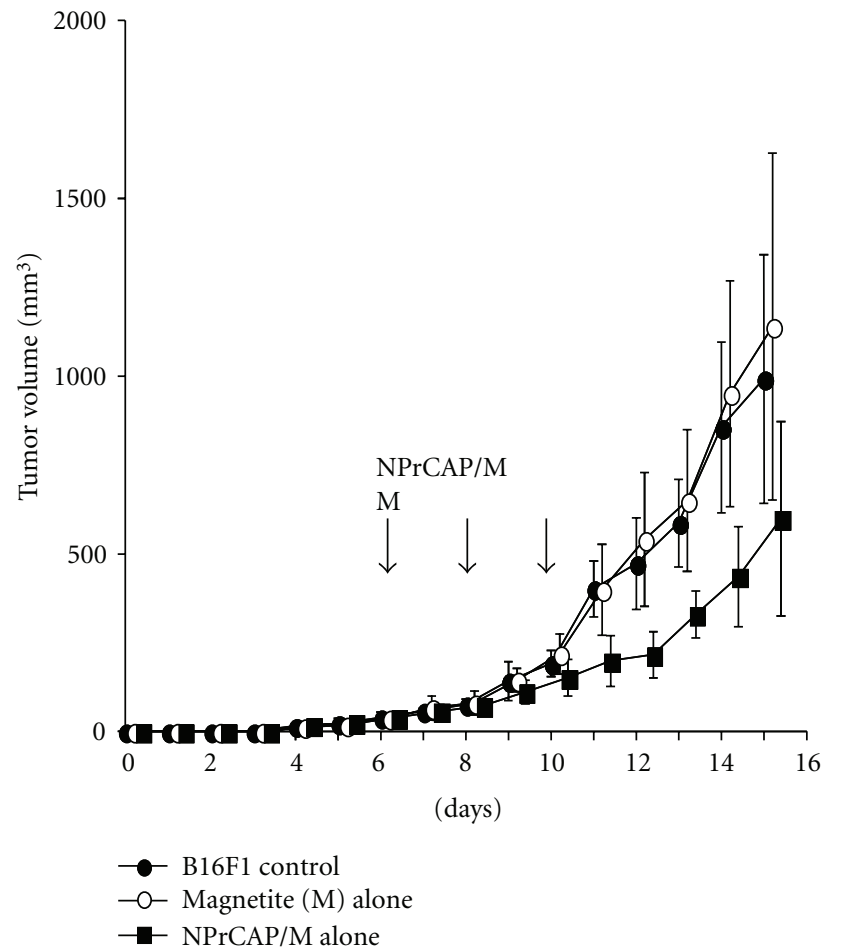

(b)

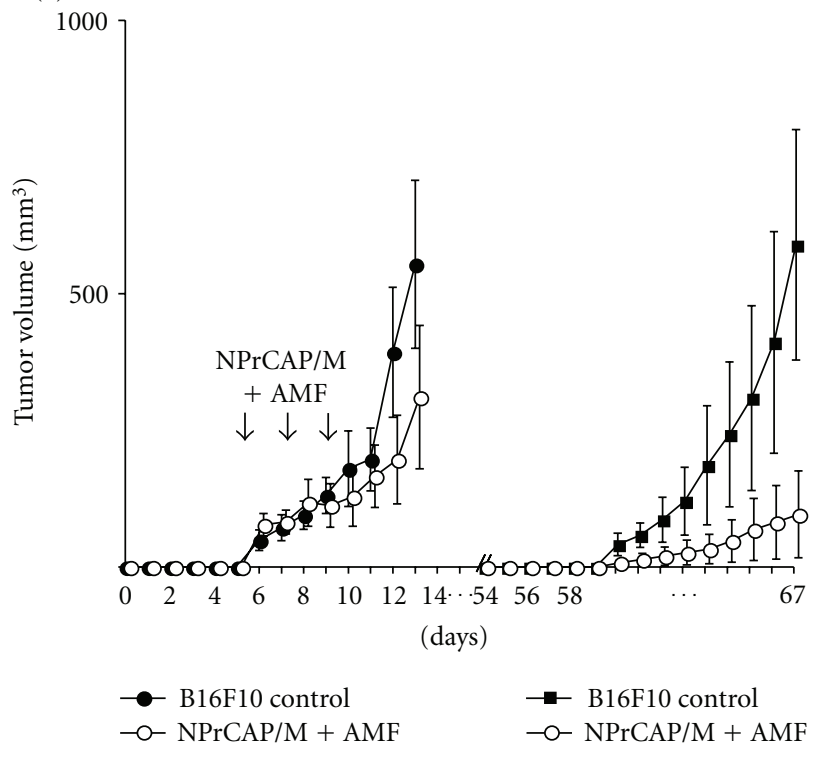

(c)

(d)

FIGURE 2: Growth curves of primary B16 melanomas. Experimental conditions and statistical analyses of (a), (b), (c) and (d) are identical to those of Protocol number 1. (a) Growth curve of B16F1 melanoma cells treated with NPrCAP/M alone without heat $(n=10)$ and with heat by AMF exposure $(n=10)$ at days 6,8 , and 10 . These two groups showed a significant growth inhibition compared to that of control naive mice $(n=10)$ by Dunnet's test $(P<.01)$. Importantly, there is no significant difference between the two groups with and without AMF exposure. (b) Growth curve of B16F1 melanoma cells treated with magnetite alone $(n=10)$ and NPrCAP/M alone without AMF exposure $(n=10)$. Mice with magnetite alone did not show any growth inhibition whereas NPrCAP/M alone resulted in a significant growth inhibition of primary melanoma $(P<.01)$. (c) Comparison of growth inhibition of B16F10 primary melanomas after treatment with $\mathrm{NPrCAP} / \mathrm{M}$ with AMF exposure. Compared to control naive mice $(n=10)$ transplanted with B16F10 cells without any treatment, those mice $(n=10)$ with NPrCAP/M plus AMF exposure showed a significant growth inhibition of primary B16F10 melanomas with a similar degree to that of B16F1 melanoma (Figure 2(a)) $(P<.01$ by Dunnet's test). (d) Comparison of the growth inhibition of B16F10 secondary, re-challenge melanoma. The mice $(n=10)$ with NPrCAP/M plus AMF exposure showed a marked growth inhibition compared to control naive mice without any treatment $(n=10)$. 
melanoma cells into the opposite flank. Tumor volumes were calculated at day 14 after the second transplantation of B16 melanoma cells.

2.4.2. Protocol Number 2: Effect of Treatment Frequency with NPrCAP/M on Re-Challenge Tumor Growth. Mice were randomly divided into six treatment groups. They were exposed to AMF once on day 6 (Group I), twice (on days 6 and 8) (Group II), twice (on days 6 and 10) (Group III), three times (on days 6, 8, and 10) (Group IV), three times (on days 6, 7, and 8) (Group V), and five times (on days 6 through 10) (Group VI).

\subsubsection{Protocol Number 3: Effect of Temperature and Treatment} Frequency of NPrCAP/M with AMF on Re-Challenge Tumor Growth. Mice were divided into six groups. Mice of Groups I and II were exposed to the AMF to maintain the surface temperature at $41^{\circ} \mathrm{C}$ once a day for two days (days 6 and 10) and for three days (days 6, 8, and 10), respectively. Using the same day schedule mice of Groups III and IV were exposed to the AMF at $43^{\circ} \mathrm{C}$ and mice of Groups V and VI at $46^{\circ} \mathrm{C}$.

\subsubsection{Protocol Number 4: Effect of Temperature and Treatment} Duration on Re-Challenge Tumor Growth. Mice were divided into four groups. Temperatures at the surface of the tumors in Groups I and II were maintained at $43^{\circ} \mathrm{C}$ and $46^{\circ} \mathrm{C}$, respectively, during AMF exposure for 15 minutes. The surface temperatures in Groups III and IV were maintained at $43^{\circ} \mathrm{C}$ and $46^{\circ} \mathrm{C}$, respectively, during therapy for 30 minutes.

2.5. ELISA for Heat Shock Protein 70 (HSP70) Expression in a Tumor. After thermotherapy, the amount of HSP70 in the primary tumor was measured using an HSP70 EIA Kit (Stress Gen Biotechnologies, British Columbia, Canada) according to the manufacturer's instructions. The total protein content of the tumor homogenates was determined using the BCA Protein Assay Kit (Pierce Biothechnology, Inc., USA). The control group was composed of mice without NPrCAP/M administration or AMF exposure. Group I received s.c. administration of NPrCAP/M directly at the tumor site once a day without AMF exposure. Mice of Groups II and III received thermotherapy at $41^{\circ} \mathrm{C}$ for 15 minutes and 30 minutes, Groups IV and V at $43^{\circ} \mathrm{C}$ for 15 minutes and 30 minutes, and Groups VI and VII at $46^{\circ} \mathrm{C}$ for 15 minutes and 30 minutes, respectively. Then, 24 hours later, all tumors were removed, and their lysates were processed for the HSP70 assay. In separate groups, tumors were excised at 24,48 , and 72 hours after the $43^{\circ} \mathrm{C}$ thermotherapy for 30 minutes, and amounts of HSP70 were measured.

2.6. Histological and Immunohistochemical Study. After thermotherapy in the primarily transplanted melanoma at $43^{\circ} \mathrm{C}$ for 30 minutes once a day for three days (Figure 4(a), Group IV), melanomas in re-challenge mice were excised on the 18th day after second transplantation of B16F1 cells. Paraffin-embedded sections were prepared and processed for
HE staining. The frozen tumor tissues were stained with antimouse CD4 (Santa Cruz Biotechnology Inc., CA, USA) or CD8 (Chemicon International Inc., CA, USA).

2.7. Statistical Analysis. Data were analyzed by one- or twoway analysis of variance (ANOVA), and then differences in experimental results for tumor growth and expression of HSP were assessed by Sheffe's test to compare all the experimental groups, or by Dunnett's test, which compared the experimental versus the control groups. Differences in survival rates were analyzed by the Kaplan-Meier method and log-rank test with Bonferroni correction for multiple comparisons. The level of significance was $P<.05$ (twotailed). All statistical analyses were performed using Stat View J-5.0 (SAS Institute Inc. Cary, NC).

\section{Results and Discussion}

In the search for successful cancer treatment it is self-evident that the exploitation of a specific biological property is one of the best approaches for developing the targeted therapy $[27,28]$. We have previously shown that the melanogenesis substrate, NPrCAP, is a good candidate for developing melanoma chemotherapy because melanogenesis is uniquely expressed in melanocytic cells and is inherently cytotoxic from the action of tyrosinase on tyrosine with formation of highly reactive free radicals $[1,4]$. Nanoparticles may also provide a good platform to coadminister anticancer therapeutics directed at different targets. Specifically hyperthermia with the use of magnetite nanoparticles has been shown to possess great potential to develop thermoimmunotherapy $[23,29]$. In this study the conjugate of NPrCAP and magnetite nanoparticles, NPrCAP/M was synthesized with the hope of developing a chemotherapeutic as well as a thermo-immunotherapeutic effect. We employed two cell lines of B16 melanoma, that is, B16F1 and B16F10, and B16OVA cells and compared the thermo-therapeutic protocols in detail by evaluating the growth of the rechallenge melanoma as well as the duration and rates of survival of melanoma-bearing mice.

3.1. Immediate and Steady Generation of Heat by Intratumor Administration of NPrCAP/M with AMF Exposure on B16 Melanoma Nodules. In the previous intratumor MCL hyperthermia for B16 melanoma the skin surface temperature above the subcutaneous tumor rose to 43 or $46^{\circ} \mathrm{C}$ [29]. To obtain a rapid and steady temperature increase at the core and the surface of the B16 melanoma, NPrCAP/M was injected into the center of the tumor nodules, and internal and surface tumor temperatures were measured during AMF exposure. Both temperatures increased within one minute to the target of $41^{\circ} \mathrm{C}, 43^{\circ} \mathrm{C}$, or $46^{\circ} \mathrm{C}$ (Figures $1(\mathrm{a}), 1(\mathrm{~b})$, and $1(\mathrm{c})$ ), indicating that $\mathrm{NPrCAP} / \mathrm{M}$ injection followed by AMF exposure could immediately and steadily heat the subcutaneously transplanted melanoma nodules. The temperature at the tumor center was approximately $2^{\circ} \mathrm{C}$ higher than that at the tumor surface. 


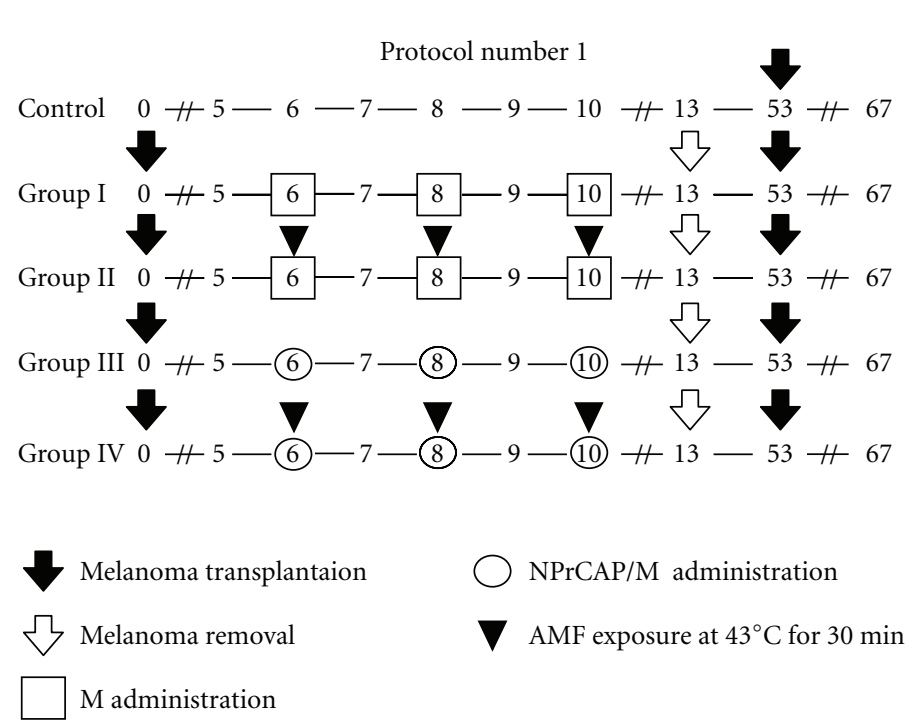

(a)

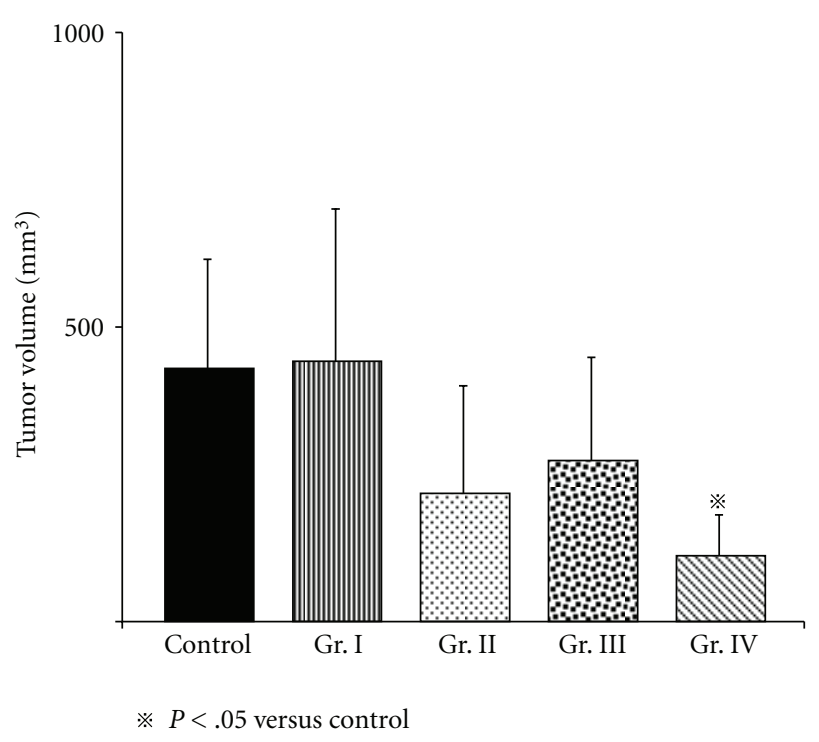

(b)

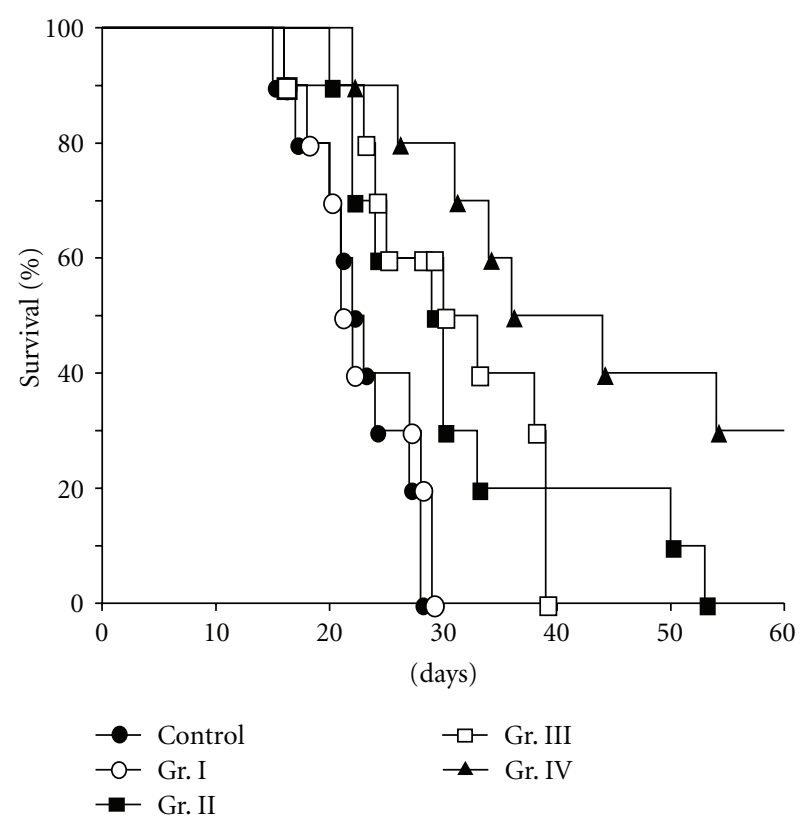

(c)

Figure 3: Time schedules and results for tumor volumes, survival periods, and rates of mice treated by the Protocol number 1 . (a) Protocols of Groups I, II, III, and IV. (b) Tumor volumes of re-challenge B16F1 melanoma on day 14. All data are presented as mean \pm standard deviation. Tumor volumes of Group IV were significantly reduced compared with those of the control group $(P=.0295)$ or Group I $(P=.0215)$. There were no significant interactions between drugs and AMF $(P=.5568)$. (c) Kaplan-Meier survival curve over a period of 60 days after tumor re-challenge in Protocol number 1.

3.2. Effective and Equal Inhibition of B16 Melanoma Growth at the Site of Primary Transplantation by Intratumor Administration of $N P r C A P / M$ with and without Heat. We first evaluated the chemotherapeutic effect of NPrCAP/M with or without heat. NPrCAP/M without heat inhibited the growth of primary transplants to the same degree as did $\mathrm{NPrCAP} / \mathrm{M}$ with heat, indicating that NPrCAP/M alone has a chemotherapeutic effect. The critical temperature for thermotherapy was documented to be $43^{\circ} \mathrm{C}$ for various cell lines $[7,8]$. Using two melanoma cell lines, B16F1, and B16F10 and B16OVA, we examined melanoma growth inhibition by intra-tumor administration of NPrCAP/M into primary tumors on days 6,8 , and 10 after transplantation with exposure to $\mathrm{AMF}$ at $43^{\circ} \mathrm{C}$ for 30 minutes (Figures 2(a) and 2(c)) under the experimental conditions of Protocol number 1 (Figure 3(a)). Both NPrCAP/M with and without AMF exposure resulted in a significant and equal reduction of melanoma tumor volume in both $\mathrm{B} 16 \mathrm{~F} 1$ and $\mathrm{F} 10$ cells 


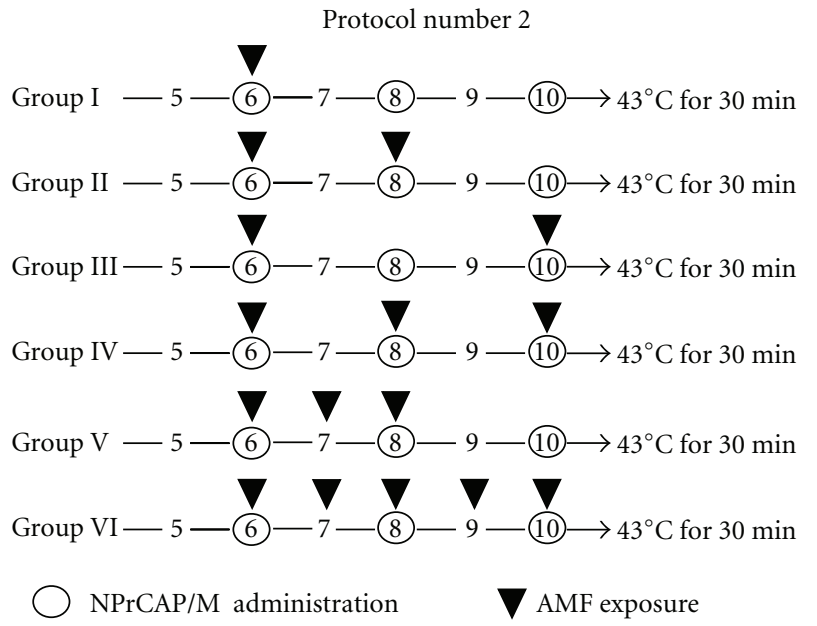

(a)

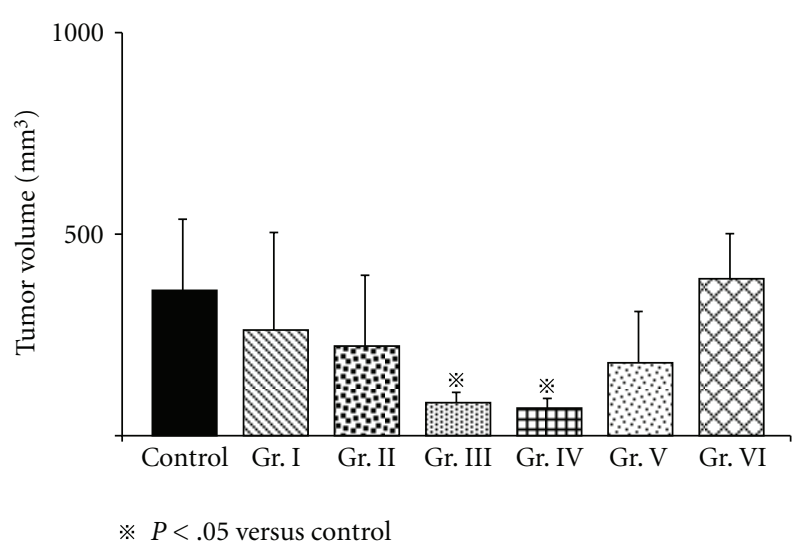

(b)



(c)

Figure 4: Time schedule and results for tumor volumes, survival periods, and rates of mice treated by Protocol number 2. (a) Protocols of Groups I, II, III, IV, V, and VI. (b) Tumor volumes on day 14 after re-challenge with B16F1 melanoma. All data are presented as mean \pm standard deviation. Tumor volumes of Groups III and IV were found to be significantly reduced compared with those of the control group $(P=.0411$ and .0195 , resp. $)$ and Group VI $(P=.0444$ and .0237 , resp. $)$ by the Scheffé test. (c) Kaplan-Meier survival curves over a period of 60 days after re-challenge with B16F1. The survival rate of Group III was significantly prolonged compared with those of the control group $(P=.0006)$ and Group VI $(P=.0013)$. The survival rate of Group IV was significantly prolonged compared with that of the control group $(P<.0001)$, Group I $(P=.0014)$, Group II $(P=.0014)$, and Group VI $(P=.0013)$. One of the eight mice in Group III and three of the nine mice in Group IV were protected against re-challenge with B16F1 melanoma cells.

at the site of primary transplantation $(P<.01$ by twoway repeated measure ANOVA, Figures 2(a) and 2(c)) compared to tumor volume of naive control mice. B16 OVA cells also gave the same experimental results (data not shown). Control studies comparing magnetite alone and magnetite plus NPrCAP (NPrCAP/M) without AMF exposure showed that magnetite alone does not have any melanoma growth inhibiting effect whereas NPrCAP/M without AMF significantly inhibited melanoma-growth $(P<$ .01 by two-way repeated measure ANOVA, Figure 2(b)). Since we obtained basically same growth inhibition results for both the primary and secondary transplants from the 


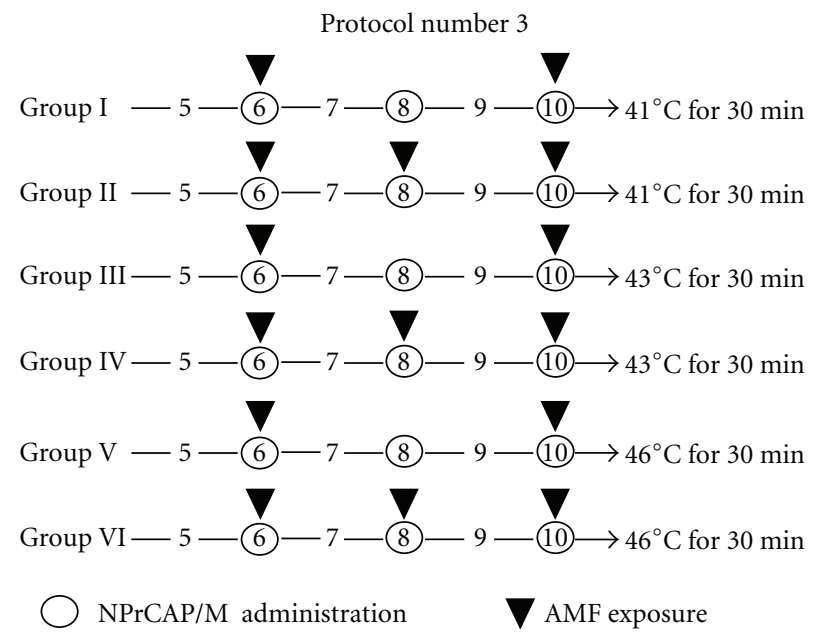

(a)

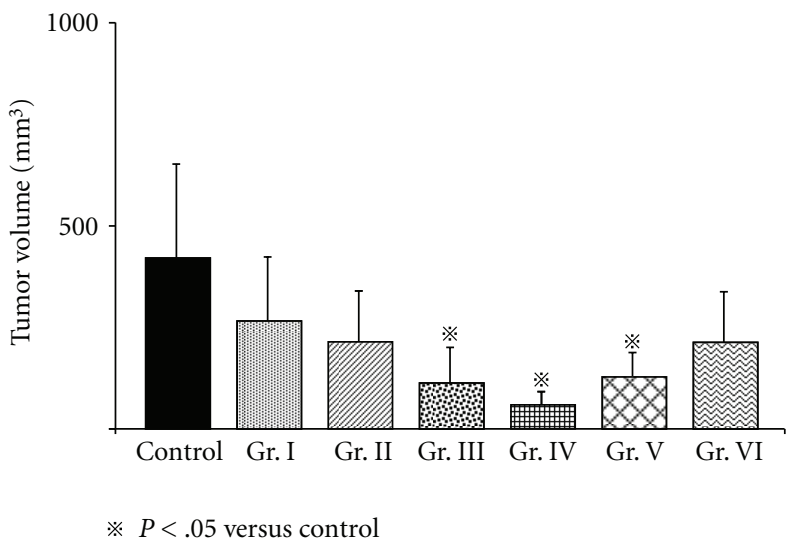

(b)

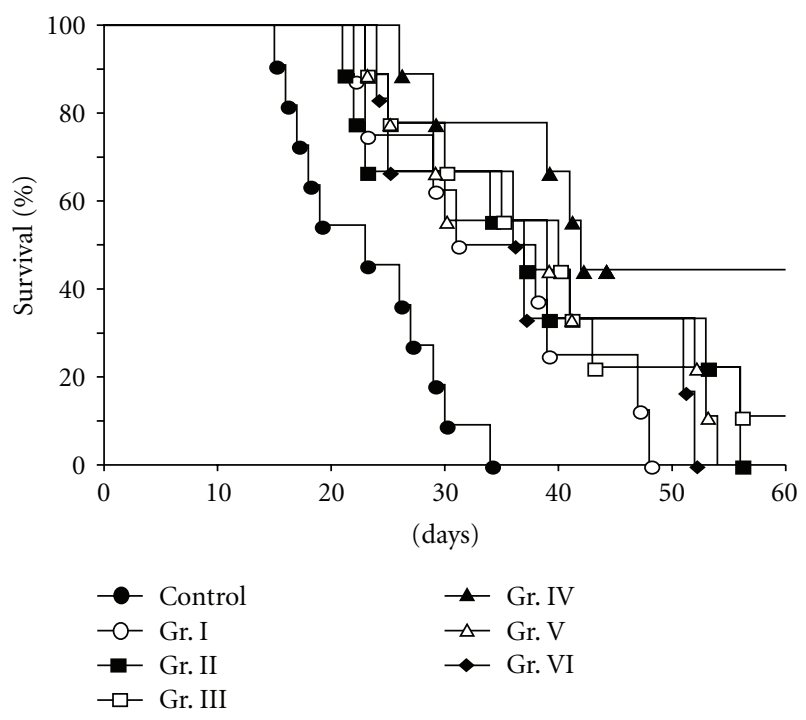

(c)

Figure 5: Time schedules and results for tumor volume, survival periods and rates of mice treated by Protocol number 3. (a) Protocols of Groups I, II, III, IV, V, and VI. (b) Tumor volumes on day 14 after re-challenge with B16F1 melanoma. All data are presented as mean \pm standard deviation. Tumor volumes of Groups III, IV, and V were significantly reduced compared with the control group $(P=.0045, .0004$, and .0085 resp.) by the Scheffé test. (c) Kaplan-Meier survival curve over a period of 60 days after tumor re-challenge. Survival rates of Groups III and IV were significantly prolonged compared with that of the control group $(P=.0011$ and .0002 , resp. $)$. One of the nine mice in Group III and four of the nine mice in Group IV were protected against re-challenge with B16F1 melanoma cells.

two cell lines, the majority of subsequent studies listed in Protocols number 1 through number 4 were conducted on B16F1 cells.

3.3. Effective Growth Inhibition of B16F1 Melanoma Cells at the Site of Re-Challenge, Second Transplantation by NPrCAP/M with AMF Exposure (Protocol number 1). We then evaluated whether NPrCAP/M treatment with or without heat in the local primary tumor could inhibit the growth of distant tumors which were not given an intratumor injection of NPrCAP/M. There was a significant difference in the melanoma growth inhibition of re-challenge transplants between the groups of NPrCAP/M with and without heat. NPrCAP/M with AMF exposure showed the most significant growth inhibition in re-challenge melanoma and increased life span of the host animals, that is, 30\%$50 \%$ complete growth inhibition (rejection) of re-challenge melanoma growth, indicating that NPrCAP/M with heat possesses a thermo-immunotherapeutic effect. For this, we treated the primary $\mathrm{B} 16 \mathrm{~F} 1$ and $\mathrm{F} 10$ melanoma cells by $\mathrm{NPrCAP} / \mathrm{M}$ and then measured the volume of the secondary melanoma after the second transplantation at a different site to the first transplant. We also evaluated the survival periods 


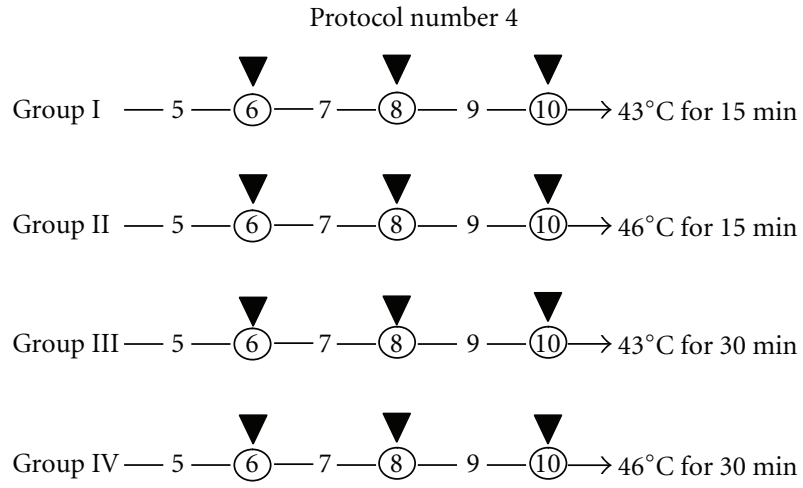

NPrCAP/M administration

(a)



(c)

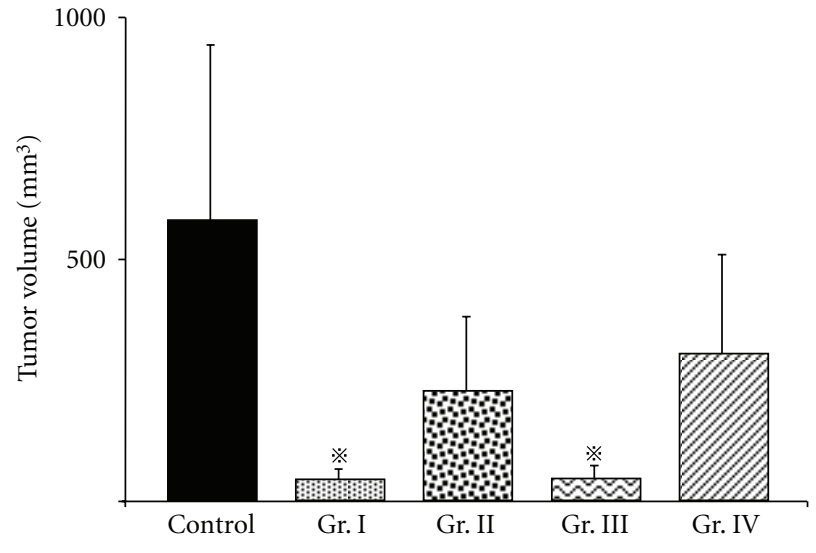

※ $P<.05$ versus control

(b)

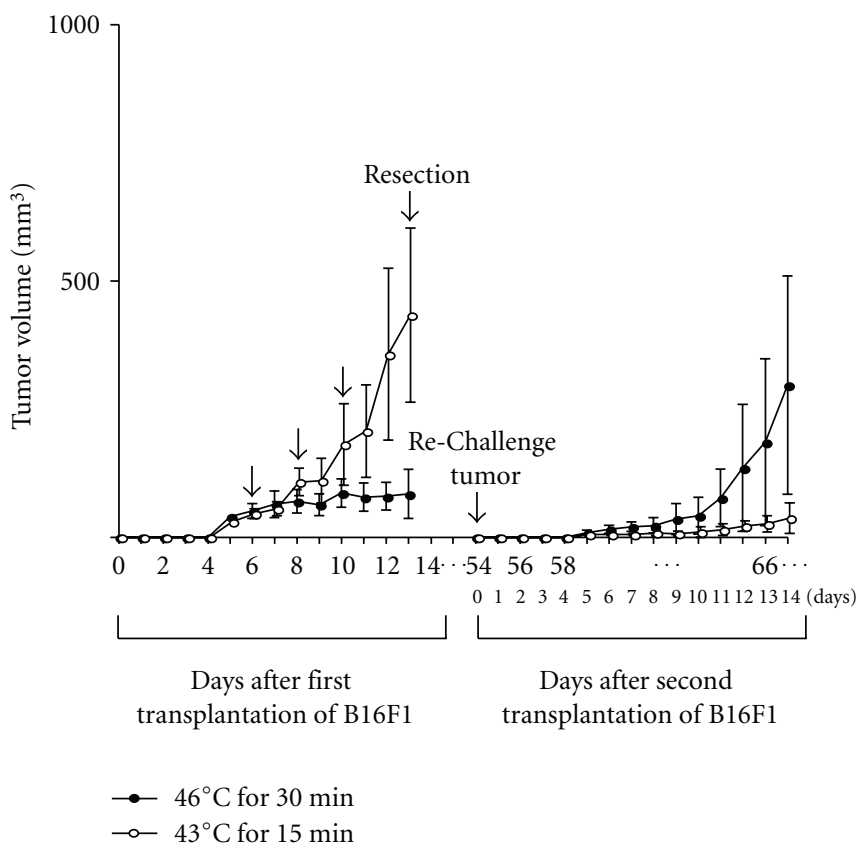

(d)

Figure 6: Time schedules and results for tumor volumes, survival periods, and rates for treatment with Protocol number 4. (a) Protocols of Groups I, II, III, and IV. (b) Tumor volumes on day 14 after re-challenge with B16F1 cells. All data are presented as mean \pm standard deviation. Tumor volumes of Groups I and III on day 14 were significantly reduced compared with that of the control group $(P=.0009$ and .0016, resp.) by Scheffé test. (c) Kaplan-Meier survival curve over a period of 60 days after re-challenge. Survival rates of Group I and III were significantly prolonged compared with that of the control group $(P=.0004$ and .0005 , resp.). Four of the eight mice in Group I and three of the seven mice in Group III were protected against re-challenge with B16F1 melanoma cells. (d) Tumor volumes of the primary tumor and re-challenge tumor as representative examples of Groups I $(n=8)$ and IV $(n=10)$ which were treated at $43^{\circ} \mathrm{C}$ for 15 minutes and $46^{\circ} \mathrm{C}$ for 30 minutes, respectively. All data are presented as mean \pm standard deviation.

and rates of host melanoma-bearing mice. These secondary melanomas were not directly exposed to NPrCAP/M; hence we could evaluate the thermo-immunotherapeutic effect of $\mathrm{NPrCAP} / \mathrm{M}$ treatment.

First, we compared the therapeutic effects among Groups I (intratumor injection of magnetite nanoparticles alone without AMF exposure), II (magnetite injection and heat at $43^{\circ} \mathrm{C}$ for 30 minutes by $\mathrm{AMF}$ ), III (NPrCAP/M injection without $\mathrm{AMF}$ ), and IV (NPrCAP/M injection and heat at $43^{\circ} \mathrm{C}$ for 30 minutes by AMF) of Protocol number 1 (Figure 3(a)). As shown in Figure 3(b), NPrCAP/Mmediated hyperthermia at $43^{\circ} \mathrm{C}$ showed the most significant 


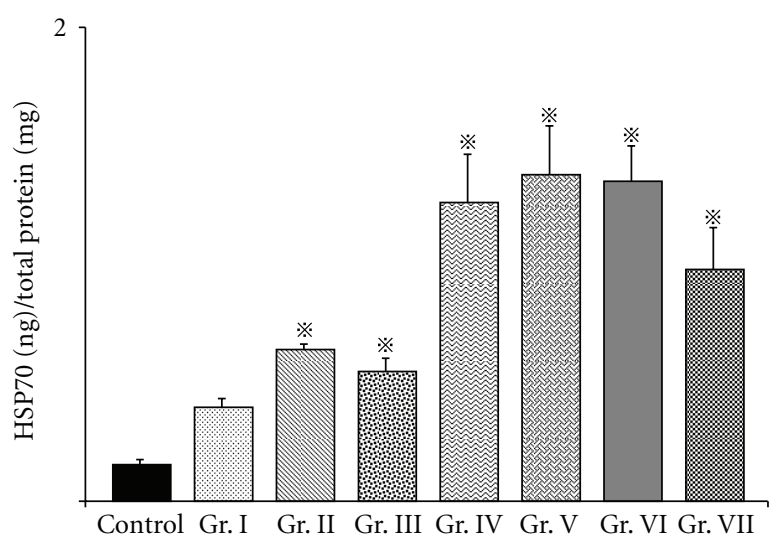

(a)

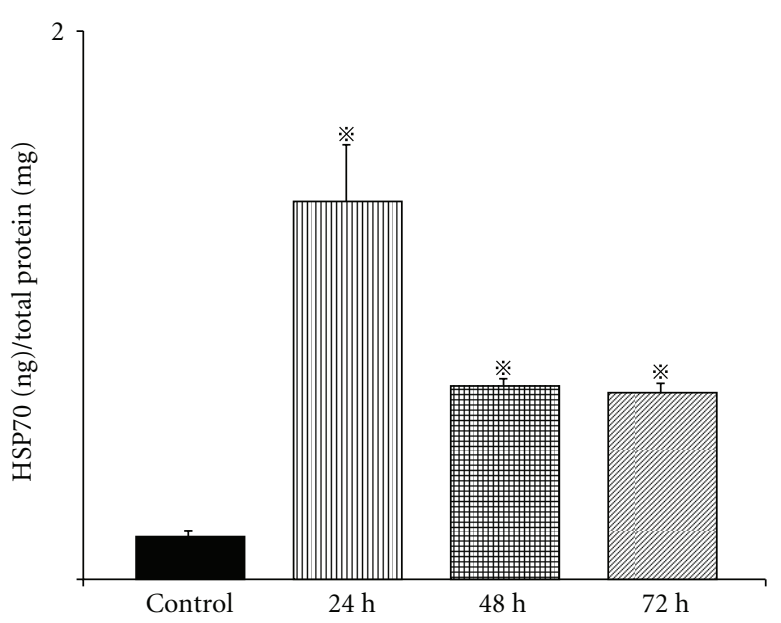

(b)

FIGURE 7: Expression of HSP70 in a tumor after thermotherapy. (a) Amounts of HSP70 in tumors 24 hours after thermotherapy as described in the Materials and Methods. All data are presented as mean \pm standard deviation $(n=4)$. There were significant differences between the control group and all other groups except Group I by Dunnett's test $(P<.05)$. (b) Amounts of HSP70 24, 48, and 72 hours after thermotherapy at $43^{\circ} \mathrm{C}$ for 30 minutes. All data are presented as mean \pm standard deviation $(n=4)$. There were significant differences between the control group and all other groups by Dunnett's test $(P<.05)$.

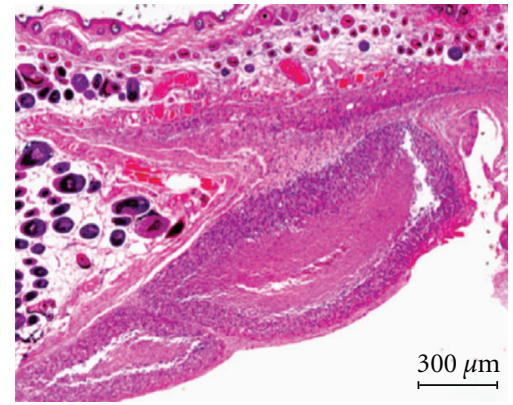

(a)

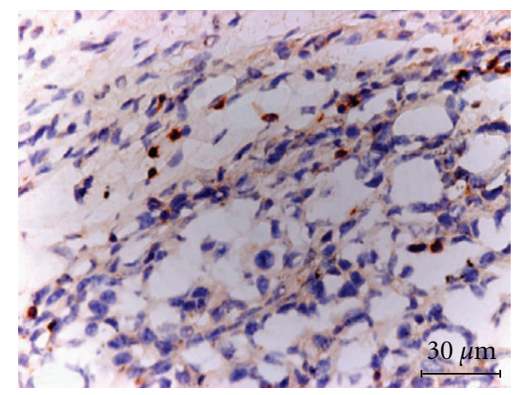

(c)

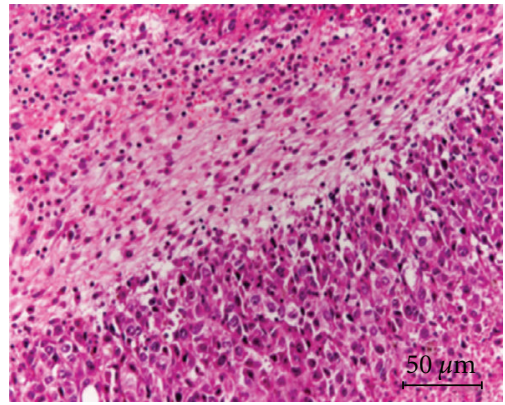

(b)

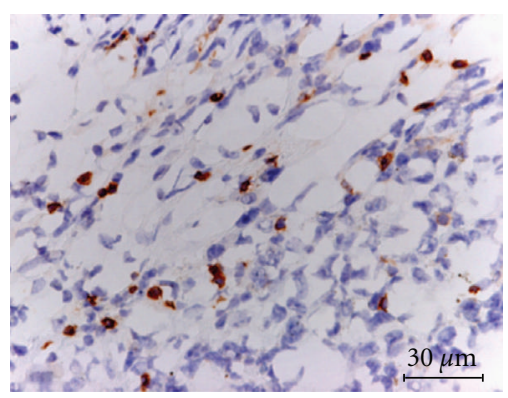

(d)

FIGURE 8: Histopathology and immunohistochemistry of a re-challenge tumor. (a) A low-power view of a re-challenge tumor with HE staining $(\times 49)$. (b) A high-power view $(\times 200)$. Monocytic infiltrates are seen around a necrotic lesion. $(\mathrm{c}) \mathrm{CD}^{+} \mathrm{T}$ cells $(\times 400)$. $(\mathrm{d}) \mathrm{CD} 8^{+} \mathrm{T}$ cells $(\times 400)$. Almost equal numbers of $\mathrm{CD}^{+}$and $\mathrm{CD}^{+} \mathrm{T}$ cells are observed.

growth inhibition of secondary B16F1 melanoma in rechallenged mice. Both magnetite nanoparticles with heat at $43^{\circ} \mathrm{C}$ and NPrCAP/M without heat also inhibited the growth of secondary melanomas, though statistically not significant (Figure 3(b) and (c)). Most importantly, NPrCAP/M alone without heat caused equal growth inhibition of secondary melanomas to that induced by magnetite with AMF exposure, suggesting some immunotherapeutic effect of NPrCAP/M. A similar growth inhibition of secondary transplanted melanoma cells was obtained in B16F10 (Figure 2). 
Next, we compared the life span of the host animals among 4 groups. The survival of mice in Group IV was prolonged, compared with that of the control group $(P=$ $.0003)$ and Group I $(P=.0003)$. Three of the ten mice in Group IV (30\%) were protected completely from rechallenge with B16F1 cells (Figure 3(c)). Magnetite alone with AMF exposure at $43^{\circ} \mathrm{C}$ (Group II) and NPrCAP/M alone without heat (Group III) failed to show any statistically significant prolongation of the host animal survival.

3.4. Effect of Treatment Frequency for the Primary Tumor on Growth Inhibition of Re-Challenge Melanoma (Protocol number 2). To evaluate the effect of the number of treatments for the primary tumor on the re-challenge tumor, six treatment approaches were designed using B16F1 cells. They consisted of hyperthermia once on day 6 (Group I), twice on days 6 and 8 (Group II) or days 6 and 10 (Group III), three times on days 6,8 , and 10 (Group IV) or 6,7 , and 8 (Group V), and a total of five times on days 6 through 10 (Group VI) (Figure 4(a)). Melanoma tumor volumes in rechallenged mice were smallest in Groups III and IV, while the longest survival periods and rates were obtained in Group IV with complete growth inhibition (rejection) of second re-challenge being $33 \%(n=9)$ on day 60 (Figures $4(\mathrm{~b}$ ) and $4(\mathrm{c})$ ). The consecutive irradiation on days 6,7 , and 8 (Group V) or days 6 through 10 resulted in larger volumes of secondary tumors and poorer survival periods and rates compared to Group III or IV (Figures 4(b) and 4(c)). These findings suggested that repeated hyperthermia, once a day every other day for a total of three days, could induce effective degradation of B16 melanoma cells, which then most likely induced host immunity against melanoma.

3.5. Effect of Temperature and Treatment Frequency on Melanoma Growth Inhibition in Re-Challenge Mice (Protocol number 3). Our study indicated that the most effective thermo-immunotherapy for re-challenge B16 melanoma can be obtained at a temperature of $43^{\circ} \mathrm{C}$ for 30 minutes with the treatment repeated three times on every other day intervals without complete degradation of the primary melanoma. We compared growth inhibition of secondly transplanted melanomas at therapeutic temperatures of $41^{\circ} \mathrm{C}, 43^{\circ} \mathrm{C}$, and $46^{\circ} \mathrm{C}$ for 30 minutes twice on days 6 and 10 , or three times on days 6, 8, and 10 (Figure 5(a)). As shown in Figures 5(b) and 5 (c), thermotherapy at $43^{\circ} \mathrm{C}$ in Group IV $\left(43^{\circ} \mathrm{C}\right.$, every other day for a total of three times on three days) was the most effective for the growth inhibition of both the secondly transplanted, re-challenge melanoma and for improving the survival rates and duration of host mice. Four of the nine mice in Group IV (44.4\%) were protected completely against re-challenge with B16F1 melanoma on day 60 (Figure 5(c)).

Our therapeutic conditions and their effects differ from those of magnetically mediated hyperthermia on the transplanted melanomas reported previously [29]. MCLmediated hyperthermia for B16 melanoma showed that hyperthermia at $46^{\circ} \mathrm{C}$ once or twice led to regression of $40 \%-90 \%$ of primary tumors and to $30 \%-60 \%$ survival of mice, whereas hyperthermia at $43^{\circ} \mathrm{C}$ failed to induce regression of the secondary tumors with $0 \%$ survival of mice [29].

3.6. Effect of Temperature and Treatment Duration on Melanoma Growth Inhibition in Re-Challenge Mice (Protocol number 4). We then compared the effects of temperature and duration of NPrCAP/M-mediated hyperthermia at $43^{\circ} \mathrm{C}$ for 15 minutes, $43^{\circ} \mathrm{C}$ for 30 minutes, $46^{\circ} \mathrm{C}$ for 15 minutes, and $46^{\circ} \mathrm{C}$ for 30 minutes on the re-challenge with $\mathrm{B} 16 \mathrm{~F} 1$ melanoma (Figure 6(a)). Tumor volumes and survival rates and periods of treatment of mice clearly showed that hyperthermia at $43^{\circ} \mathrm{C}$ elicited a more significant effect than that at $46^{\circ} \mathrm{C}$ (Figures 6(b) and 6(c)). Four of the eight mice $(50 \%)$ in Group I $\left(43^{\circ} \mathrm{C}\right.$ for 15 minutes) and three of the seven mice $(42.8 \%)$ in Group III $\left(43^{\circ} \mathrm{C}\right.$ for 30 minutes) survived 60 days after a second transplantation of B16F1 (Figure 6(c)), suggesting that NPrCAP/M with heat to the primary melanoma at $43^{\circ} \mathrm{C}$ for $15-30$ minutes inhibits significantly the growth of distant metastatic melanoma, complete growth inhibition (rejection) of the second rechallenge melanoma being $42 \%-50 \%$. Hyperthermia at $46^{\circ} \mathrm{C}$ for 30 minutes strongly inhibited the growth of the B16F1 tumor but had little effect on the re-challenge tumor, whereas hyperthermia at $43^{\circ} \mathrm{C}$ for 15 minutes hardly inhibited the growth of the primary tumor but strongly inhibited that of the second re-challenge tumor (Figure 6(d)). These findings suggest that NPrCAP/M-mediated hyperthermia at $43^{\circ} \mathrm{C}$ can be used most effectively to treat distant metastatic melanoma.

3.7. Production of HSP70 by NPrCAP/M Treatment and Presence of $\mathrm{CDS}^{+} \mathrm{T}$ Cells around and within the ReChallenge Melanoma. Heat shock protein forms a complex with intracellular peptides released from degrading tumor cells and presented by the MHC class I molecules of professional antigen-presenting cells [23]. We analyzed HSP70 production in the primary tumor and $\mathrm{CD}_{4}^{+}$and $\mathrm{CD} 8^{+}$ $\mathrm{T}$ cell infiltration into the re-challenge secondary tumor. Figure 7(a) shows the amounts of HSP70 in the tumors at 24 hours after the NPrCAP/M-mediated hyperthermia. Among the six treatment groups, conditions of hyperthermia at $43^{\circ} \mathrm{C}$ for 15 or 30 minutes and $46^{\circ} \mathrm{C}$ for 15 minutes were equally effective for induction of HSP70 as those at $41^{\circ} \mathrm{C}$ for 15 minutes or 30 minutes and at $46^{\circ} \mathrm{C}$ for 30 minutes (Figure $7(\mathrm{a})$ ). We also investigated whether expression of HSP70 in the posttherapeutic tumors depended on the duration of AMF exposure (15 minutes or 30 minutes), heating temperature $\left(41^{\circ} \mathrm{C}, 43^{\circ} \mathrm{C}\right.$, or $\left.46^{\circ} \mathrm{C}\right)$, and time elapsed after exposure ( 24 hours, 48 hours, or 72 hours). Figure 7 (b) shows that the amount of HSP70 in the treated B16F1 tumors was most abundant at 24 hours after hyperthermia at $43^{\circ} \mathrm{C}$, and over-expression of HSP70 was maintained at a significant level after 72 hours. Although thermotherapy at $46^{\circ} \mathrm{C}$ for 15 minutes could induce HSP70 as abundantly as that at $43^{\circ} \mathrm{C}$ for 30 minutes (Figure $7(\mathrm{a})$ ), this condition failed to suppress the re-challenge melanoma transplant as 
efficiently as $43^{\circ} \mathrm{C}$ thermotherapy (Figures 5(b) and 5(c)). This suggests that immunological factors other than HSPs are at least in part responsible for growth inhibition and rejection of the re-challenge melanoma. Hyperthermia at $43^{\circ} \mathrm{C}$ for 1 hour mediated the expression of MHC class I molecules after 24 hours in association with enhanced expression of HSP70 [30]. Heat treatment of tumor cells permits enhanced cross-priming, possibly via up-regulation of both HSPs and tumor antigen expression [24]. By inducing HSP70 and possibly MHC class I, immune T cells could aggregate around melanoma cells. We thus examined histochemically the immunological reaction against secondly transplanted, re-challenge B16F1 melanoma in hematoxylin and eosin (HE)- and CD4- and CD8-stained sections. In addition to neutrophilic leukocytes, macrophages, and plasma cells, $\mathrm{CD}^{+}{ }^{+}$and $\mathrm{CD} 8^{+} \mathrm{T}$ cells were observed around and within the re-challenge tumors with necrotic lesions (Figures $8(\mathrm{a}), 8(\mathrm{~b}), 8(\mathrm{c})$, and $8(\mathrm{~d})$ ). These $\mathrm{T}$ cells were seen with a small number around the first transplant melanoma treated by NPrCAP/M with or without AMF exposure but hardly observed around the naive B16F1 tumors in mice that were not treated by NPrCAP/M-mediated thermotherapy (data not shown). This may indicate that melanoma-specific $\mathrm{T}$ cell immunity is likely involved in our NPrCAP/M therapy strategy.

\section{Conclusions}

This study has provided the basis for developing a melanoma targeted chemo-immuno-thermotherapy (CTI) strategy by conjugating melanogenesis substrate, NPrCAP with magnetite nanoparticles after exposure to alternating magnetic field. NPrCAP/M-mediated hyperthermia at a relatively low temperature $\left(43^{\circ} \mathrm{C}\right)$ effectively inhibited the growth of second transplant, re-challenge melanoma. Possibly, superficially bound NPrCAP possesses important roles in targeting nanoparticles to melanocytic cells and a chemotherapeutic effect on these cells. Based upon the present animal therapeutic protocol, that is, three-every-other-day treatment at $43^{\circ} \mathrm{C}$, we have started preliminary clinical trials (phase I/II) of NPrCAP/M CTI therapy with a significant success to a limited number of advanced stages III and IV melanoma patients. Four patients entered in this trial after approval of the Ethics Committee of Sapporo Medical University and two of them showed PR and CR, still surviving and carrying out normal daily life for more than 24 months [31].

Lastly, it should be noted that melanin intermediates produce reactive oxygen species such as superoxide and $\mathrm{H}_{2} \mathrm{O}_{2}$ $[4,32,33]$. This unique biological property of melanin intermediates not only causes cell death but also may produce immunogenic properties. In fact, NPrCAP/M alone without heat was as effective as magnetite nanoparticles with AMF exposure in inhibiting growth of re-challenge melanoma (Figures 3(b) and 3(c)). It would be interesting to know whether the growth of secondary re-challenge melanoma could be inhibited after treatment of NPrCAP alone onto the primary tumor [34]. The molecular background of our NPrCAP/M CTI therapy needs to be further studied.

\section{Acknowledgments}

The authors thank Toda Kogyo Co. (Hiroshima, Japan) and Meito Sangyo Co., Ltd. (Nagoya, Japan) for supplying magnetite nanoparticles and technical advice for the synthesis of NPrCAP/M, respectively. This work was supported by a Health and Labor Sciences Research Grant-in-Aid for Research on Advanced Medical Technology from the Ministry of Health, Labor and Welfare of Japan (H21-Nano006). they wish to express their appreciation to Ms. Masae Okura for the technical help in conducting this research.

\section{References}

[1] K. Jimbow, T. Iwashina, F. Alena, K. Yamada, J. Pankovich, and T. Umemura, "Exploitation of pigment biosynthesis pathway as a selective chemotherapeutic approach for malignant melanoma," The Journal of Investigative Dermatology, vol. 100, supplement 2, pp. 231S-238S, 1993.

[2] F. Alena, T. Iwashina, A. Gili, and K. Jimbow, "Selective in vivo accumulation of $\mathrm{N}$-acetyl-4-S-cysteaminylphenol in B16F10 murine melanoma and enhancement of its in vitro and in vivo antimelanoma effect by combination of buthionine sulfoximine," Cancer Research, vol. 54, no. 10, pp. 2661-2666, 1994.

[3] J. M. Pankovich and K. Jimbow, "Tyrosine transport in a human melanoma cell line as a basis for selective transport of cytotoxic analogues," Biochemical Journal, vol. 280, no. 3, pp. 721-725, 1991.

[4] K. Reszka and K. Jimbow, "Electron donor and acceptor properties of melanin pigments in the skin," in Oxidative Stress in Dermatology, J. Fuchs and L. Packer, Eds., pp. 287-320, Marcel Dekker, New York, NY, USA, 1993.

[5] M. Tandon, P. D. Thomas, M. Shokravi, et al., "Synthesis and antitumour effect of the melanogenesis-based antimelanoma agent N-Propionyl-4-S-cysteaminylphenol," Biochemical Pharmacology, vol. 55, no. 12, pp. 2023-2029, 1998.

[6] P. D. Thomas, H. Kishi, H. Cao, et al., "Selective incorporation and specific cytocidal effect as the cellular basis for the antimelanoma action of sulphur containing tyrosine analogs," The Journal of Investigative Dermatology, vol. 113, no. 6, pp. 928-934, 1999.

[7] O. Algan, H. Fosmire, K. Hynynen, et al., "External beam radiotherapy and hyperthermia in the treatment of patients with locally advanced prostate carcinoma," Cancer, vol. 89, no. 2, pp. 399-403, 2000.

[8] M. D. Hurwitz, I. D. Kaplan, J. L. Hansen, et al., "Association of rectal toxicity with thermal dose parameters in treatment of locally advanced prostate cancer with radiation and hyperthermia," International Journal of Radiation Oncology, Biology, Physics, vol. 53, no. 4, pp. 913-918, 2002.

[9] M. Johannsen, U. Gneveckow, L. Eckelt, et al., "Clinical hyperthermia of prostate cancer using magnetic nanoparticles: presentation of a new interstitial technique," International Journal of Hyperthermia, vol. 21, no. 7, pp. 637-647, 2005.

[10] N. Kawai, A. Ito, Y. Nakahara, et al., "Anticancer effect of hyperthermia on prostate cancer mediated by magnetite cationic liposomes and immune-response induction in transplanted syngeneic rats," Prostate, vol. 64, no. 4, pp. 373-381, 2005.

[11] S. Lindquist, "The heat-shock response," Annual Review of Biochemistry, vol. 55, pp. 1151-1191, 1986. 
[12] A. Konno, N. Sato, A. Yagihashi, et al., "Heat- or stressinducible transformation-associated cell surface antigen on the activated H-ras oncogene-transfected rat fibroblast," Cancer Research, vol. 49, no. 23, pp. 6578-6582, 1989.

[13] A. Ménoret and R. Chandawarkar, "Heat-shock protein-based anticancer immunotherapy: an idea whose time has come," Seminars in Oncology, vol. 25, no. 6, pp. 654-660, 1998.

[14] P. K. Srivastava, A. Ménoret, S. Basu, R. Binder, and K. Quade, "Heat shock proteins come of age: primitive functions acquired new roles in an adaptive world," Immunity, vol. 8, no. 6, pp. 657-665, 1998.

[15] Y. Tamura, N. Tsuboi, N. Sato, and K. Kikuchi, " 70 kDa heat shock cognate protein is a transformation-associated antigen and a possible target for the host's anti-tumor immunity," The Journal of Immunology, vol. 151, no. 10, pp. 5516-5524, 1993.

[16] Y. Tamura, P. Peng, K. Liu, M. Daou, and P. K. Srivastava, "Immunotherapy of tumors with autologous tumor-derived heat shock protein preparations," Science, vol. 278, no. 5335, pp. 117-120, 1997.

[17] D. D. Mosser, A. W. Caron, L. Bourget, C. Denis-Larose, and B. Massie, "Role of the human heat shock protein hsp70 in protection against stress-induced apoptosis," Molecular and Cellular Biology, vol. 17, no. 9, pp. 5317-5327, 1997.

[18] Y. Tamura and N. Sato, "Heat shock proteins: chaperoning of innate and adaptive immunities," Japanese Journal of Hyperthermic Oncology, vol. 19, pp. 131-139, 2003.

[19] P. K. Srivastava, "Immunotherapy for human cancer using heat shock protein-peptide complexes," Current Oncology Reports, vol. 7, no. 2, pp. 104-108, 2005.

[20] S. Takashima, N. Sato, A. Kishi, et al., "Involvement of peptide antigens in the cytotoxicity between $70-\mathrm{kDa}$ heat shock cognate protein-like molecule and $\mathrm{CD}^{+}, \mathrm{CD} 4^{-}, \mathrm{CD} 8^{-}$, TCR- $\alpha \beta$ - killer T cells," The Journal of Immunology, vol. 157, no. 8, pp. 3391-3395, 1996.

[21] M. Yanase, M. Shinkai, H. Honda, T. Wakabayashi, J. Yoshida, and T. Kobayashi, "Antitumor immunity induction by intracellular hyperthermia using magnetite cationic liposomes," Japanese Journal of Cancer Research, vol. 89, no. 7, pp. 775782, 1998.

[22] G. Ueda, Y. Tamura, I. Hirai, et al., "Tumor-derived heat shock protein 70-pulsed dendritic cells elicit-tumor-specific cytotoxic T lymphocytes (CTLs) and tumor immunity," Cancer Science, vol. 95, no. 3, pp. 248-253, 2004.

[23] A. Ito, H. Honda, and T. Kobayashi, "Cancer immunotherapy based on intracellular hyperthermia using magnetite nanoparticles: a novel concept of "heat-controlled necrosis" with heat shock protein expression," Cancer Immunology, Immunotherapy, vol. 55, no. 3, pp. 320-328, 2006.

[24] H. Shi, T. Cao, J. E. Connolly, et al., "Hyperthermia enhances CTL cross-priming," The Journal of Immunology, vol. 176, no. 4, pp. 2134-2141, 2006.

[25] A. Ito, M. Fujioka, T. Yoshida, et al., "4-S-cysteaminylphenolloaded magnetite cationic liposomes for combination therapy of hyperthermia with chemotherapy against malignant melanoma," Cancer Science, vol. 98, no. 3, pp. 424-430, 2007.

[26] M. Sato, T. Yamashita, M. Ohkura, et al., "N-propionylcysteaminylphenol-magnetite conjugate (NPrCAP/M) is a nanoparticle for the targeted growth suppression of melanoma cells," The Journal of Investigative Dermatology, vol. 129, no. 9, pp. 2233-2241, 2009.

[27] A. A. Brozyna, L. VanMiddlesworth, and A. T. Slominski, "Inhibition of melanogenesis as a radiation sensitizer for melanoma therapy," International Journal of Cancer, vol. 123, no. 6, pp. 1448-1456, 2008.
[28] A. Slominski, B. Zbytek, and R. Slominski, "Inhibitors of melanogenesis increase toxicity of cyclophosphamide and lymphocytes against melanoma cells," International Journal of Cancer, vol. 124, no. 6, pp. 1470-1477, 2009.

[29] M. Suzuki, M. Shinkai, H. Honda, and T. Kobayashi, "Anticancer effect and immune induction by hyperthermia of malignant melanoma using magnetite cationic liposomes," Melanoma Research, vol. 13, no. 2, pp. 129-135, 2003.

[30] A. Ito, M. Shinkai, H. Honda, T. Wakabayashi, J. Yoshida, and T. Kobayashi, "Augmentation of MHC class I antigen presentation via heat shock protein expression by hyperthermia," Cancer Immunology, Immunotherapy, vol. 50, no. 10, pp. 515$522,2001$.

[31] K. Jimbow, T. Takada, M. Sato, et al., "Melanin biology and translational research strategy; melanogenesis and nanomedicine as the basis for melanoma-targeted DDS and chemothermo-immunotherapy," Pigment Cell and Melanoma Research, vol. 21, no. 2, p. 243, 2008.

[32] K. Jimbow, Y. Miyake, K. Homma, et al., "Characterization of melanogenesis and morphogenesis of melanosomes by physicochemical properties of melanin and melanosomes in malignant melanoma," Cancer Research, vol. 44, no. 3, pp. 1128-1134, 1984.

[33] Y. Minamitsuji, K. Toyofuku, S. Sugiyama, and K. Jimbow, "Sulphur containing tyrosinase analogs can cause selective melanocytoxicity involving tyrosinase-mediated apoptosis," The Journal of Investigative Dermatology, vol. 4, no. 2, pp. 130S-136S, 1999.

[34] Y. Osai, M. Ohkura, Y. Tamura, et al., "Intratumoral administration of melanoma targeting N-propionyl cysteaminylphenol induces in vivo anti-melanoma effect and tumor specific immunity," Pigment Cell \& Melanoma Research, vol. 21, no. 2, p. 329, 2008. 


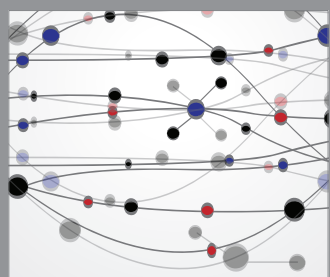

The Scientific World Journal
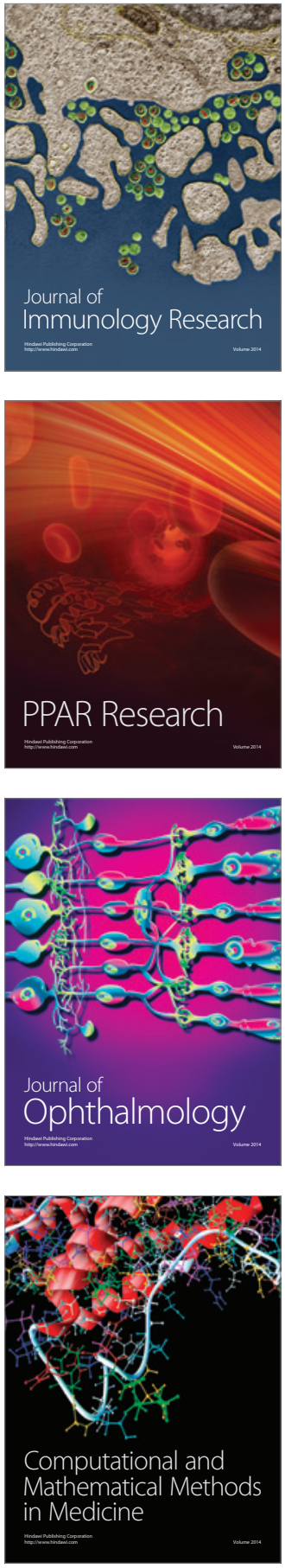



Gastroenterology

Research and Practice
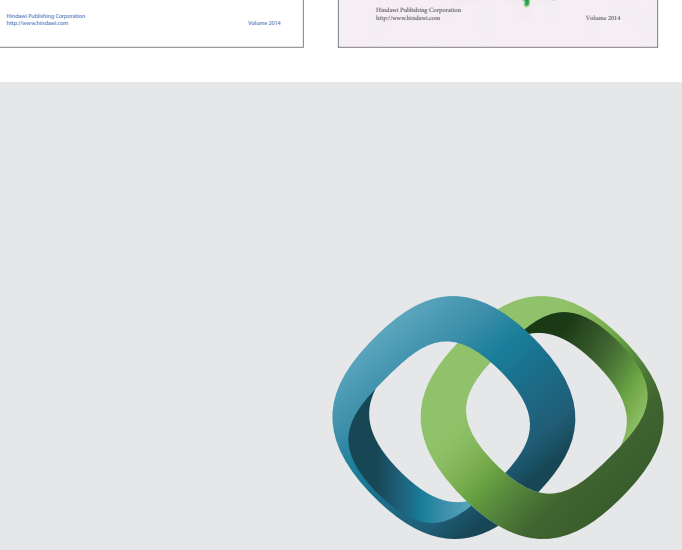

\section{Hindawi}

Submit your manuscripts at

http://www.hindawi.com
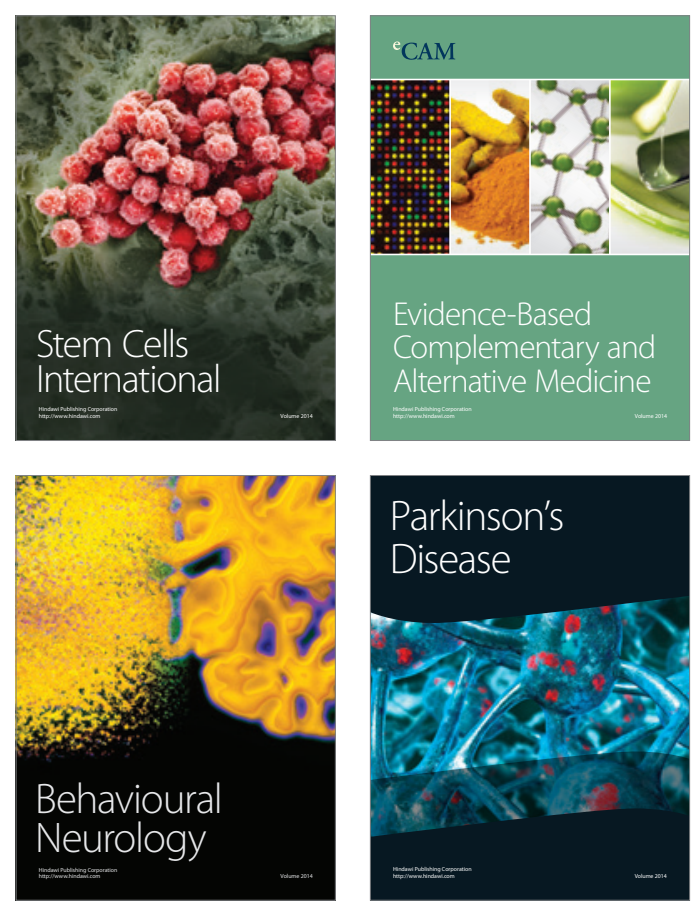

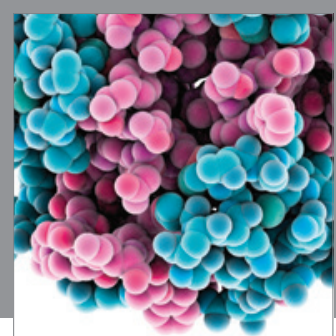

Journal of
Diabetes Research

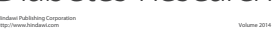

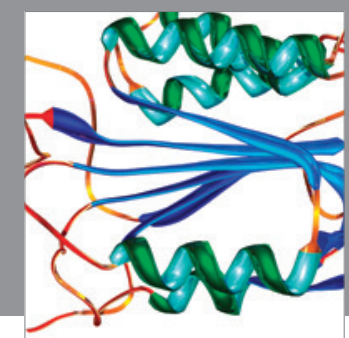

Disease Markers
